\title{
Simultaneous observations of the main trough using GPS imaging and the EISCAT radar
}

\author{
R. W. Meggs ${ }^{1}$, C. N. Mitchell ${ }^{1}$, and V. S. C. Howells ${ }^{2}$ \\ ${ }^{1}$ Department of Electronic and Electrical Engineering, University of Bath, BA2 7AY Bath, UK \\ ${ }^{2}$ Rutherford-Appleton Laboratory, Chilton, OX11 0QX, UK
}

Received: 5 January 2005 - Revised: 10 January 2005 - Accepted: 21 January 2005 - Published: 30 March 2005

\begin{abstract}
Images of the winter-time ionosphere over Northern Scandinavia in January 2002 from two independent experimental techniques are presented. In the first case, observations of differential phase delay from the GPS satellites are used in an inversion algorithm, called MIDAS (Multi Instrument Data Analysis Software), to estimate the spatial distribution of electron concentration. The second approach uses the European Incoherent Scatter (EISCAT) radar situated near Troms $\varnothing$ in northern Norway to gather independent data for comparison with the MIDAS images. The EISCAT data are plotted as "fan plots" that show electron concentration as a function of latitude and range, whilst the MIDAS results are presented in the form of latitude-altitude crosssections at the locations and times coincident with the radar scans. Wide-area maps of Total Electron Content (TEC) are also shown for the post-noon period. The position and time evolution of the trough seen in the MIDAS images is confirmed by four scans of the EISCAT radar in the afternoon period. The results demonstrate that GPS imaging is capable of locating the main trough, and confirm the potential of MIDAS imaging as a tool for routine monitoring of the ionosphere.
\end{abstract}

Keywords. Radio science (Ionospheric propagation; Remote sensing; Space and satellite communication)

\section{Introduction}

Over the past quarter century, the European Incoherent Scatter (EISCAT) radar has become well established as a tool for observing the ionosphere, both above and below the F2 peak, and is capable of measuring a wide range of ionospheric parameters. Good spatial resolution can be obtained owing to the narrow beam pattern of the antenna, which is large in relation to the radio wavelength (Hargreaves, 1992). Beynon and Williams (1978) present a discussion on the early history and development of incoherent scatter radar, and an ex-

Correspondence to: R. W. Meggs

(eeprwm@bath.ac.uk) planation of the parameters that can be directly measured or inferred by the technique.

An important application of incoherent scatter radar has been to provide independent verification for other experimental techniques, such as ionospheric tomography (Walker et al., 1996). Ionospheric tomography was first suggested by (Austen et al., 1986), with further work reported by the same group two years later (Austen et al., 1988). Tomography involves reconstructing an image of an object using straight line projections of rays that are influenced by it in some way. In the case of ionospheric tomography, the rays can be Lband radio signals from GPS satellites. Since the ionosphere is a refractive medium, the signals suffer a phase advance and a group delay, in inverse proportion to the frequency squared and in direct proportion to the Total Electron Content (TEC). TEC is defined as the number of free electrons in a column of unit cross-sectional area along the path between a satellite $S$ and a receiver $R$. It is related to the electron concentration per unit volume, $N_{e}(s)$, by

$T E C=\int_{R}^{S} N_{e}(s) \cdot d s$

TEC can be inferred from dual frequency carrier phase and/or code phase measurements of the path length between GPS satellites and fixed ground-based receivers. Mannucci et al. (1998) describe the current approach to measuring TEC and converting it to equivalent vertical TEC.

In this paper two independent techniques have been used to view the auroral ionosphere over Northern Scandinavia. The purpose of this is to evaluate a new, low-cost ionospheric imaging technique that uses freely available GPS data. This inversion algorithm is implemented in a software suite called MIDAS (Multi Instrument Data Analysis Software), which was developed as a research tool for imaging the ionosphere using differential phase data from ground-based GPS receivers. It can also use measurements from ionosondes, satellite-mounted sea-reflecting radars and direct measurements of electron concentration using space-based GPS receivers mounted on low earth orbit (LEO) satellites. In this work it is used only with data from the ground-based GPS receivers. The output from MIDAS is a four-dimensional 


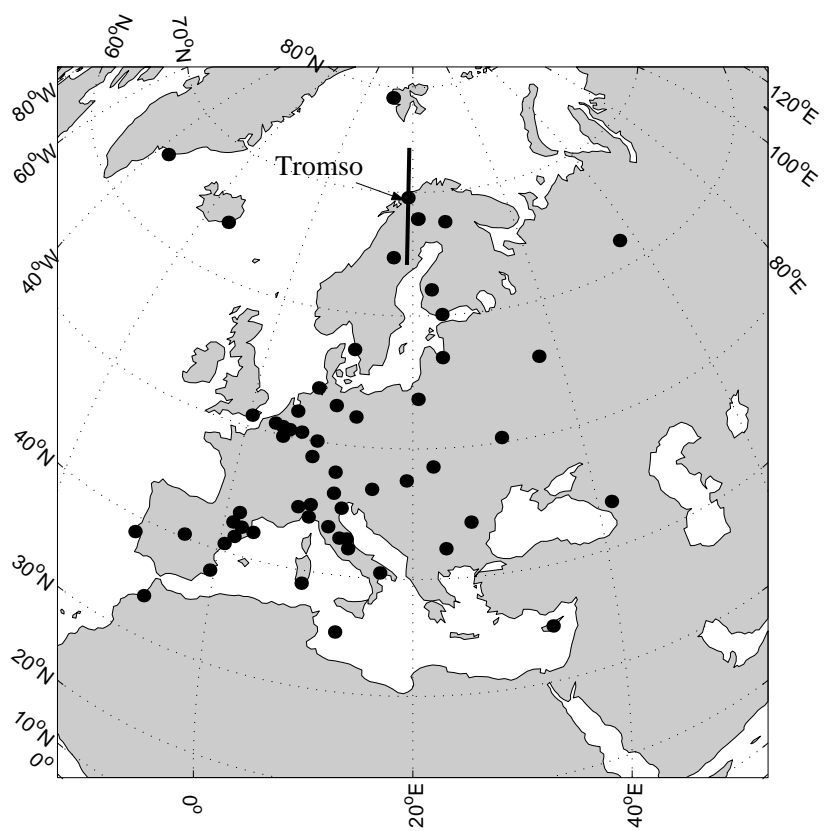

Fig. 1. Map showing locations of GPS receivers and EISCAT radar. The azimuth of the radar scan is shown passing through Troms $\emptyset$.

movie of electron concentration that can show either maps of vertical TEC over a wide geographical area, or plots of electron concentration as a function of latitude and height.

The established instrument used for validation here is the EISCAT radar. EISCAT has two radar systems on the mainland of northern Scandinavia: a VHF $(224 \mathrm{MHz})$ transmitter, and a UHF $(930 \mathrm{MHz})$ transmitter. Both transmitters are co-located with their receivers near Troms $\emptyset$, Norway, at Lat. $69.587^{\circ} \mathrm{N}$, Long. $19.227^{\circ} \mathrm{E}$, a position that often places it below the structures of the auroral ionosphere. Two further UHF receivers, at Kiruna in Sweden and Sodankylä in Finland, enable the UHF radar to operate as a tristatic system if required (Rishbeth and Williams, 1985). In the study presented here, the radar was operated in the monostatic mode.

\section{Method}

The MIDAS algorithm, described by Mitchell and Spencer (2003), can be summarized as follows. Observations of slant TEC are made to GPS satellites in view from a number of ground-based fixed dual-frequency GPS receivers. A grid of three-dimensional elements (called "voxels" to distinguish them from two-dimensional pixels) is set up in a spherical volume to represent the region of the ionosphere that it is required to image. On the assumption that the electron density, $\mathrm{x}$, within each voxel is constant, the problem can be defined as a system of linear equations, thus

$\mathbf{A x}=\boldsymbol{b}$

in which the $\mathbf{A}$ is a sparse matrix of the path lengths in each voxel, $\boldsymbol{x}$ is the vector of electron densities in each voxel, and $\boldsymbol{b}$ is a vector containing the observed path length integrals. Since $\mathbf{A}$ is known and $\boldsymbol{b}$ is the quantity measured, the problem is to solve Eq. (2) for $\boldsymbol{x}$. This will permit vertical TECs to be estimated for any geographical position within the coverage area.

A difficulty arises in that many voxels in the reconstruction volume are not traversed by any satellite to receiver ray paths, hence the path lengths in these voxels (and so the corresponding entries in the matrix $\mathbf{A}$ ) is zero. The inclusion of a priori information will help to stabilise the solution, and the approach adopted in MIDAS uses an extension into three dimensions of the method described for twodimensional imaging by Fremouw et al. (1992). Since the ionosphere cannot be considered to be stationary during the pass of a GPS satellite, a time dependence is incorporated in the solution. Using a mapping matrix $\mathbf{M}$, Eq. (2) is transformed from a voxel-based representation to an ortho-normal representation of the reconstruction volume. This can be expressed as

$\mathbf{A M} \boldsymbol{X}=\boldsymbol{b}$

where the unknown term is $\mathbf{X}$, the relative contribution of the basis functions. When phase data are used, adjacent rows of the matrices AM and $\boldsymbol{b}$ are differenced to remove the unknown carrier cycle ambiguity. $\mathbf{X}$ can now be found by inverting Eq. (3), that is

$\boldsymbol{X}=(\mathbf{A M})^{-1} \boldsymbol{b}$

By applying singular value decomposition to the matrix $\mathbf{A M}$, two orthogonal matrices $\mathbf{U}$ and $\mathbf{V}$ are returned with a diagonal matrix of singular values, $\mathbf{w}$. Hence the solution to the inverse problem is given by

$\boldsymbol{X}=\left(\mathbf{U} \cdot \operatorname{diag}(\mathbf{w}) \cdot \mathbf{V}^{\mathrm{T}}\right) \boldsymbol{b}$

With $\boldsymbol{X}$ now known, the electron densities within each voxel can then be retrieved from Eqs. (2) and (3):

$\boldsymbol{x}=M \boldsymbol{X}$

By default, MIDAS maps from the voxel-based to the ortho-normal representation using spherical harmonics in the horizontal domain, and ortho-normal basis functions in the vertical domain. These ortho-normal basis functions may be derived from models such as Chapman or Epstein. For a discussion on resolution analysis as applied to tomographic work, see Na and Lee (1991).

In this case data from sixty GPS receivers (see Fig. 1) were used in the inversion. It can be seen that there are relatively few receivers in the north of the region. However, Mitchell, et al. (1997) have shown that ionospheric features can be imaged reliably with as few as two receivers. The GPS receiver and satellite orbital data were obtained from the Scripps Orbit and Permanent Array Center (SOPAC) archive at http://sopac.ucsd.edu/. The reconstruction grid extended over the entire globe in increments of $1^{\circ}$ latitudinally and $4^{\circ}$ longitudinally, and from $80 \mathrm{~km}$ to $1180 \mathrm{~km}$ in altitude, in increments of $50 \mathrm{~km}$. The restricted extent of the imaging 
volume used was between $30^{\circ} \mathrm{N}$ to $80^{\circ} \mathrm{N}, 10^{\circ} \mathrm{W}$ to $40^{\circ} \mathrm{E}$, and from $80 \mathrm{~km}$ to $1180 \mathrm{~km}$. The vertical profile was formed from Chapman functions. Using the IRI95 model at the horizontal centre of the grid, the electron density peak and scale heights were set to $284 \mathrm{~km}$ and $68 \mathrm{~km}$ respectively, and the peak electron density was set to $9.883 \times 10^{11}$ electrons $/ \mathrm{m}^{3}$. The geomagnetic conditions for the day were quiet to moderate, with $K_{p}$ values of less than 2.7. Under these conditions it can be expected that an empirical model such as IRI95 can give a reasonable estimate of the peak and scale heights.

The EISCAT UHF radar was operated on 7 January 2002 in a special program mode in order to provide an independent comparison to the MIDAS imaging. The radar experiment, tau3t_limb_UK@uhf, consisted of a geographical meridional scan, starting at low elevation northward $\left(21^{\circ}\right.$ elevation $)$ and scanning southward in 55 steps of $0.152^{\circ}$ in latitude defined at an altitude of $262.5 \mathrm{~km}$, with a dwell time of $30 \mathrm{~s}$. The total scan time was $30 \mathrm{~min}$, allowing $150 \mathrm{~s}$ for the radar to return to its starting position. During the north-to-south scan the transmitted signal was an alternating code (tau3t), which provides information about the electron concentration, ion and electron temperatures, and line-of-sight plasma velocity from $90-1400 \mathrm{~km}$ in range, with a range resolution of $5.4 \mathrm{~km}$ and a pre-integration period of $5 \mathrm{~s}$. This mode is mainly used for low-elevation and scanning experiments where long range coverage is needed to get data from ionospheric altitudes. The data were post-integrated at $1 \mathrm{~min}$ to improve the data quality, by adding two adjacent scanning positions. The electron densities from the radar were calibrated using contemporaneous data from the Troms $\varnothing$ dynasonde.

\section{Results}

The MIDAS inversions result in one-hour movies of the three-dimensional distribution of electron concentration. These can either be shown as plots of electron concentration or maps of TEC (by vertical integration). In this case (Figs. 2a and b) we have chosen to plot a single twodimensional slice of the electron concentration at the longitude closest to the EISCAT radar. As our MIDAS image grid was stepped in increments of $4^{\circ}$ longitude our slice actually encompasses the longitude range $18^{\circ} \mathrm{E}-22^{\circ} \mathrm{E}$. The plots are restricted in latitude to the region encompassing the EISCAT radar scans, $64^{\circ} \mathrm{N}-78^{\circ} \mathrm{N}$. The times of our images have been chosen to coincide with half-way through the EISCAT scan.

Figure $2 \mathrm{a}$ shows the electron concentration at 12:45 UT and Fig. 2b at 13:15 UT. The peak electron density height is $280 \mathrm{~km}$, and the main trough is clearly visible in both images centred around $75^{\circ} \mathrm{N}-76^{\circ} \mathrm{N}$. During this half-hour period an overall decrease in the peak electron concentration is apparent. In Fig. $2 \mathrm{a}$ the electron density can be seen to range from $2 \times 10^{11} \mathrm{~m}^{-2}$ at $75.5^{\circ} \mathrm{N}$ to $16 \times 10^{11} \mathrm{~m}^{-2}$ at $67^{\circ} \mathrm{N}$. In Fig. 2b, the electron density at $75.5^{\circ} \mathrm{N}$ is $3 \times 10^{11} \mathrm{~m}^{-2}$, whilst that at $67^{\circ} \mathrm{N}$ is $12 \times 10^{11} \mathrm{~m}^{-2}$.

Figures $2 \mathrm{c}$ and $\mathrm{d}$ show the distribution of electron concentration observed by the EISCAT radar for the scan starting

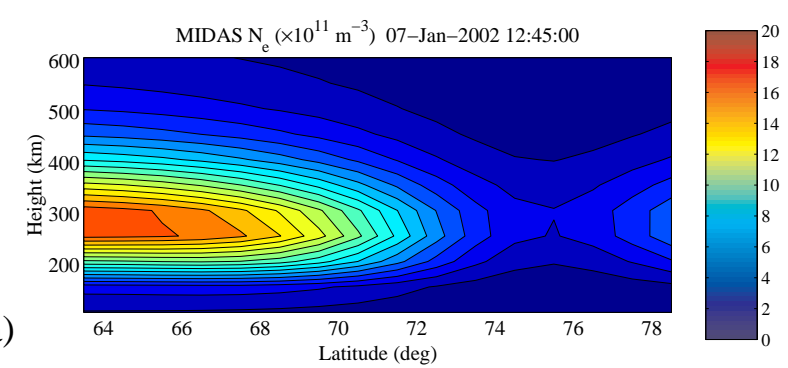

(b)

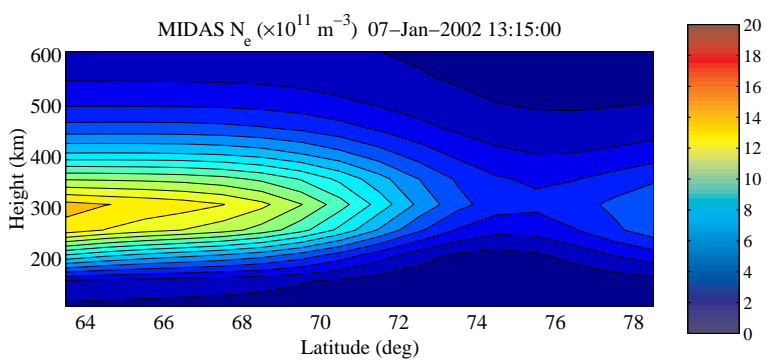

(c)
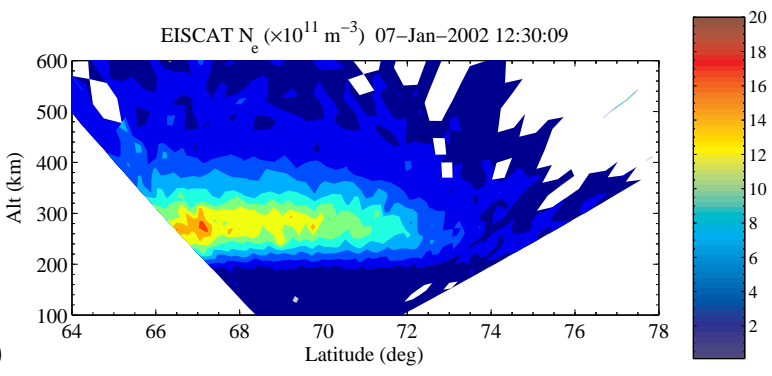

(d)

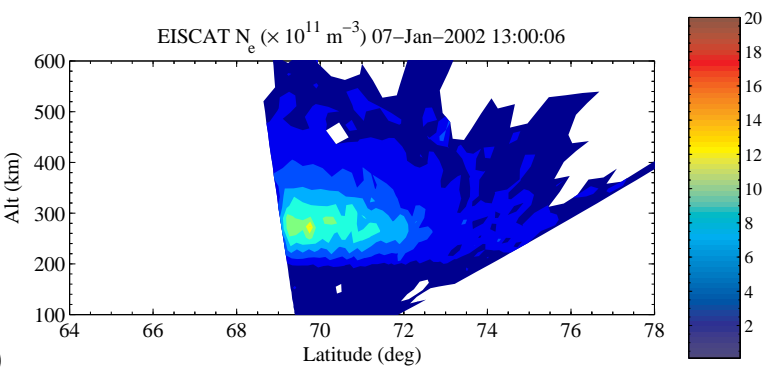

Fig. 2. Electron concentration at the longitude of the EISCAT radar between 12:30 and 13:30 UT: (a) and (b) plotted from GPS data using MIDAS; (c) and (d) plotted from EISCAT data.

at 12:31 UT and 13:00 UT respectively. In Fig. 2c, the peak electron density height is $275 \mathrm{~km}$. At $75.5^{\circ} \mathrm{N}$, the electron density is $2 \times 10^{11} \mathrm{~m}^{-2}$, whilst at $67^{\circ} \mathrm{N}$ it is $13 \times 10^{11} \mathrm{~m}^{-2}$. The scan of Fig. $2 \mathrm{~d}$ was halted prematurely due to a temporary problem with the radar. Comparing Fig. 2c back to Fig. 2a, good agreement can be seen between the two independent techniques.

Of particular interest is the overall agreement in absolute values of electron concentration. This can be partly attributed to the correct calibration of the radar observations using the dynasonde. The very small-scale structures (tens of $\mathrm{km}$ ) observed in the radar scans would not be expected to be seen by the MIDAS imaging. The applicability of the vertical profile constraints used in MIDAS (from IRI95) are to be noted - 
(a)

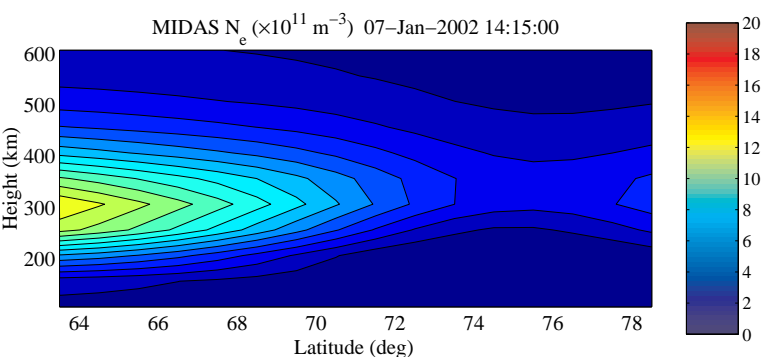

(b)

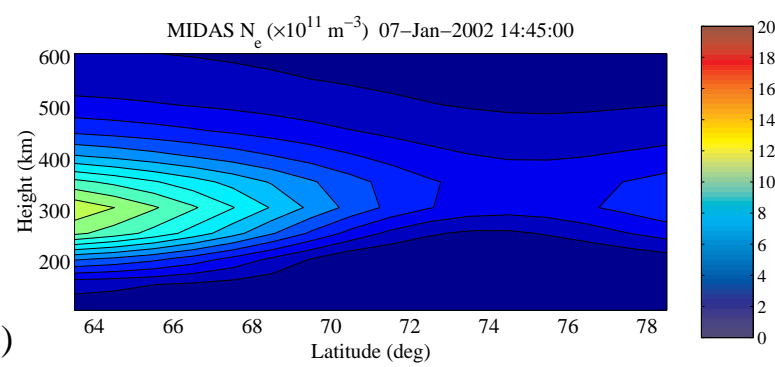

(c)
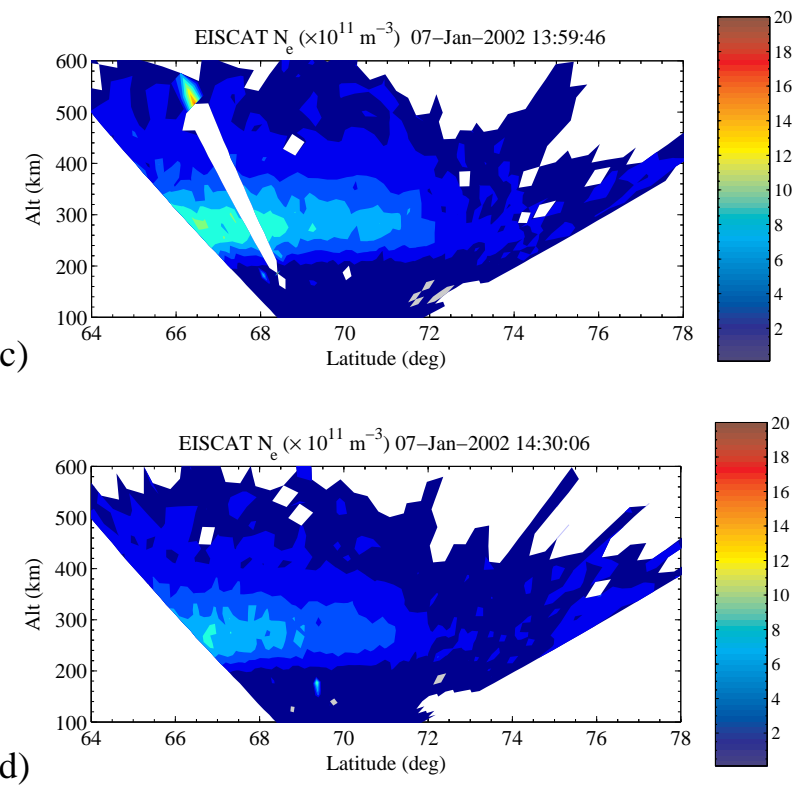

Fig. 3. Electron concentration at the longitude of the EISCAT radar between 14:00 and 15:00 UT: (a) and (b) plotted from GPS data using MIDAS; (c) and (d) plotted from EISCAT data.

the quiet ionospheric conditions have no doubt assisted in making this a suitable choice.

Figure $3 \mathrm{a}$ shows the electron concentration at 14:15 UT and Fig. $3 \mathrm{~b}$ at 14:45 UT. The main trough is clearly visible in both images centred around $74.5^{\circ} \mathrm{N}-75.5^{\circ} \mathrm{N}$. Between the two images there is an apparent southward movement of the trough, and this is confirmed by the EISCAT scans (Figs. 3c and d). Again it can be seen that the electron concentrations are decreasing over the half hour period between the two images and they have decreased over the previous hour (comparing back to Fig. 2).

In Fig. 3a the electron density can be seen to range from $2 \times 10^{11} \mathrm{~m}^{-2}$ at $75.5^{\circ} \mathrm{N}$ to $9 \times 10^{11} \mathrm{~m}^{-2}$ at $67^{\circ} \mathrm{N}$. In Fig. $3 \mathrm{~b}$, the electron density at $75.5^{\circ} \mathrm{N}$ is $3 \times 10^{11} \mathrm{~m}^{-2}$, whilst that
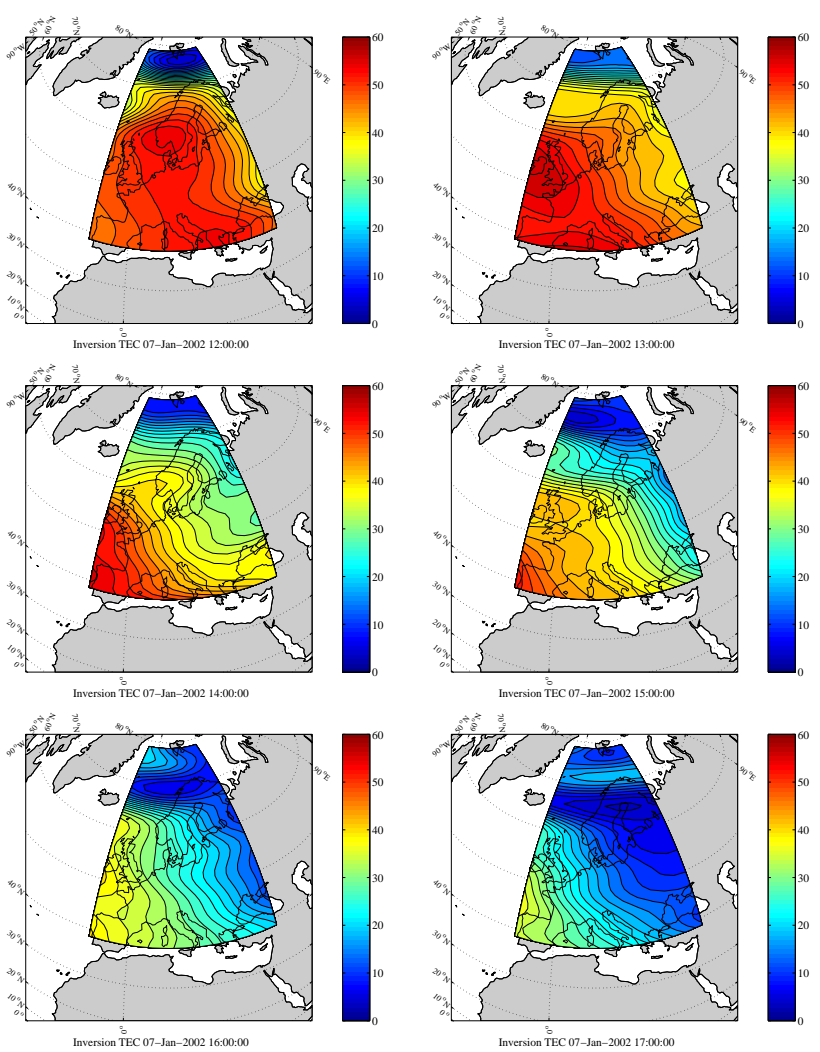

Fig. 4. Vertical TEC for each hour from 1200 to 1700 UT on 7 January 2002. Units are TEC units $\left(10^{16}\right.$ electrons $\left.\mathrm{m}^{-3}\right)$

at $67^{\circ} \mathrm{N}$ is $7 \times 10^{11} \mathrm{~m}^{-2}$. Comparing Fig. 3a with the EISCAT plot in Fig. 3c, it can be seen that the electron density at $75.5^{\circ} \mathrm{N}$, is $1 \times 10^{11} \mathrm{~m}^{-2}$, whilst at $67^{\circ} \mathrm{N}$ it is $7 \times 10^{11} \mathrm{~m}^{-2}$. At 14:30 UT the EISCAT plot shows the electron density at $75.5^{\circ} \mathrm{N}$, is $1 \times 10^{11} \mathrm{~m}^{-2}$, whilst at $67^{\circ} \mathrm{N}$ it is $7 \times 10^{11} \mathrm{~m}^{-2}$. However, these comparisons should be treated with caution, since the EISCAT images each represent a half-hour period, and the temporal and spatial variability is significant over this period.

Figure 4 shows the vertical TEC at each hour from 12:00 to 17:00 UT on 7 January 2002. The diurnal variation of the TEC in this sequence can be seen to follow that expected from the solar radiation. The main trough is clearly visible as the longitudinally distributed depletion of electron concentration moving southwards from about $74^{\circ} \mathrm{N}$ at 12:00 UT to about $65^{\circ} \mathrm{N}$ at 17:00 UT.

\section{Conclusions}

Two entirely independent experimental techniques show simultaneously the main trough over northern Scandinavia. The MIDAS images are taken from much larger spatial maps and demonstrate that dual-frequency GPS signals, monitored by a network of ground-based receivers, can be used to produce images of the main trough. These results are consistent with the expected behaviour of the main trough 
during the early afternoon in the quiet, winter-time auroral ionosphere. The EISCAT observations show very similarelectron concentrations, although they do not show the poleward wall of the trough. Hence it is difficult to be certain about the position of the trough minimum. However, the equatorward trough wall is well reproduced in both methods, and the southward movement observed in the MIDAS images is confirmed by the EISCAT images.

MIDAS imaging using GPS has a very different role to play in ionospheric physics from that served by ISRs. MIDAS can produce relatively low-resolution large area images of the ionosphere at any time since around 1995 onwards. This technique is of great interest for studying physical events such as ionospheric storms and for obtaining an overview of large-scale gradients. MIDAS images are also a new and very useful source of information for improving ionospheric models. On the other hand, ISRs can show the details of the many physical processes occurring at smaller scales (several kilometres). The confidence that can now be put into the MIDAS images should allow the two techniques to be used together to investigate physical processes in the auroral regions across multiple scale sizes.

Acknowledgements. We are grateful to the International GPS Service for the use of GPS data, and we also acknowledge the use of the IRI model. RWM also thanks BAE SYSTEMS and the UK Engineering and Physical Sciences Research Council (EPSRC) for their support. EISCAT is an International Association supported by Finland (SA), France (CNRS), the Federal Republic of Germany (MPG), Japan (NIPR), Norway (NFR), Sweden (NFR) and the United Kingdom (PPARC).

Topical Editor M. Lester thanks two referees for their help in evaluating this paper.

\section{References}

Austen, J. R., Franke, S. J., and Liu, C. H.: Application of computerized tomography techniques to ionospheric research, Radio Beacon Contributions to the Study of Ionization and Dynamics of the Ionosphere and to Corrections to Geodesy and Technical Workshop, ed. A. Tauriainen, Ouluensis Universitas, Oulu, Finland, Beacon Satellite Symposium, 1986.

Austen, J. R., Franke, S. J., and Liu, C. H.: Ionospheric imaging using computerized tomography, Radio Sci., 23, 299-307, 1988.

Beynon, W. J. G. and Williams, P. J. S.: Inchoherent scatter of radio waves from the ionosphere, Rep. Prog. Phys., 41, 910-956, 1978.

Fremouw, E. J., Secan, J. A., and Howe, B. M.: Application of stochastic inverse theory to ionospheric tomography, Radio Sci., 27, 721-732, 1992.

Hargreaves, J. K.: The solar-terrestrial environment, ISBN0-52142737-1, Cambridge University Press, 1992.

Mannucci, A. J., Wilson, B. D., Yuan, D. N., Ho, C. H., Lindqwister, U. J., and Runge, T. F.: A global mapping technique for GPSderived ionospheric total electron content measurements, Radio Sci., 33, 565-582, 1998

Mitchell, C. N., Kersley, L., and Pryse, S. E.: The effects of receiver location in two-station experimental ionospheric tomography, J. Atmos. S.-P., 59, 1411-1415, 1997.

Mitchell, C. N. and Spencer, P. S. J.: A three-dimensional timedependent algorithm for ionospheric imaging using GPS, Ann. Geophys., 46, 687-696, 2003.

Na, H. and Lee, H.: Resolution analysis of tomographic reconstruction of electron density profiles in the inosphere, Int. J. Inf. Syst. Technol., 2, 209-218, 1991.

Walker, I. K., Heaton, J. A. T., Kersley, L., Mitchell, C. N., Pryse, S. E., and Williams, M. J.: EISCAT verification in the development of ionospheric tomography, Ann. Geophys. 14, 1413-1421, 1996.

Rishbeth, H. and Williams, P. J. S.: The EISCAT ionospheric radar - the system and its early results, Quart. J. Roy. Astron. Soc., 26, 478-512, 1985. 